\title{
Formaldehyde exposure and leukaemia
}

\section{J J Collins}

\section{A new causal hypothesis?}

\begin{abstract}
"All scientific work is incompletewhether it be observational or experimental. All scientific work is liable to be upset or modified by advancing knowledge. That does not confer upon us a freedom to ignore the knowledge we already have, or to postpone the action it appears to demand at a given time." (Bradford Hill, 1965)
\end{abstract}

$\mathrm{S}$ cientific knowledge is never complete. $^{1}$ Scientists are sometimes surprised by new findings which question well established causal hypotheses. One hypothesis which has been accepted for several years and is now being questioned is that for formaldehyde carcinogenicity, particularly at low levels of exposure and in relation to cancer sites other than the upper respiratory tract.

Formaldehyde is currently classified by IARC as a probable human carcinogen based on animal studies with neoplastic lesions at the point of contact, the nasal cavity, but limited evidence of human respiratory tract carcinogenicity. ${ }^{2}$ This IARC classification is based on several long term chronic bioassays, mechanistic information developed over 20 years, and 39 epidemiology studies. The studies on formaldehyde carcinogenicity represent one of the more extensive databases that IARC has reviewed.

Formaldehyde causes nasal cavity tumours in rats and at higher exposure levels in mice. The mechanistic information seems to indicate that formaldehyde at high airborne concentrations increases the occurrence of damage to the nasal cavity and this damage contributes to "the subsequent development of cancer". ' However, there is thought to be no or little transport of formaldehyde beyond the point of contact since formaldehyde is rapidly metabolised and detoxified on contact with the upper respiratory tract. Thus, the focus of formaldehyde epidemiology for many years has been on cancers of the upper respiratory tract as evinced by 25 case-control studies examining formaldehyde exposure and sinonasal cancer, nasopharyngeal cancer, lung cancer, and cancers of oral cavity, oropharynx, and hypopharynx, and 14 cohort studies examining exposureresponse relations largely among the cancers of the respiratory tract. Rates of other cancers distant from the respiratory tract have been increased in some of the cohort studies; these findings have not received much attention.

The cohort studies of workers with formaldehyde exposures have been conducted in three broad occupational groups that have the potential to receive significant formaldehyde exposureembalmers, anatomists, and industrial workers. The industrial worker studies have more direct and quantified estimates of formaldehyde exposure relative to the other groups. ${ }^{2}$ While embalmers and anatomists have higher rates of brain cancer, lymphatic or haematopoietic cancers, and pancreatic cancers in some studies, ${ }^{3}$ the lack of higher rates of these cancers in the studies of industrial workers has been used to argue against a causal association. ${ }^{2}$ The industrial worker studies in general have leukaemia rates close to expected levels. ${ }^{3}$

Two recent updates of large industrial studies, conducted in the United States by Hauptmann et al and Pinkerton et al, have found a positive association between selected measures of formaldehyde exposure and increased leukaemia rates, ${ }^{45}$ but a recent large industry-wide study of industrial workers with formaldehyde exposure by Coggon et al in the UK failed to confirm the finding. ${ }^{\circ}$ This study, which had more workers with higher exposures than both the Hauptmann et al and the Pinkerton et al studies combined, found no increase in risk of leukaemia in the highest exposure category. There are two areas where the findings leukaemia risk conflict with our current understanding of formaldehyde carcinogenicity, the lack of consistency of the data across epidemiology studies and biological plausibility.
For many putative occupational and environmental carcinogens, there is scant mechanistic information to help focus the research or contribute to causal assessment. However, this is not the case for formaldehyde as the mechanism for cancer in laboratory animals is well understood. The proposed association between formaldehyde and leukaemia does not appear consistent with the current biological evidence. In particular: (1) no evidence of toxicity at sites remote from the respiratory tract has been found, despite multiple long term inhalation animal bioassays; (2) no DNA-protein crosslinks have been discovered in the bone marrow of rats exposed to high concentrations of formaldehyde; (3) formaldehyde does not occur in increased concentrations in blood when humans, monkeys, or rats are exposed to airborne formaldehyde; and (4) even very high concentrations of formaldehyde do not seem to cause cytogenetic damage in the lymphocytes and bone marrows of rats. ${ }^{2}$

New scientific findings in this well established field are useful because they force us to reconsider the evidence and determine what additional research may be needed to improve our understanding of the causal process. In the case of formaldehyde exposure and leukaemia, two research approaches seem possible. First, the two recent industrial studies which report a leukaemia effect should be critically reviewed to rule out uncontrolled confounding as far as possible and to assess the appropriateness of the comparison group that led to such unexpected findings. This approach could be pursued quickly, but would probably not bring the issue to resolution. Second, all of the available information should now be evaluated systematically to specify the additional research we need. Such additional research might include a formal evaluation of the leukaemia risk in previously published cohort epidemiological studies, updating some of the older investigations, formally analysing leukaemia rates by exposure level in all of the cohort studies, and investigating which mechanisms, if any, would allow formaldehyde to cause leukaemia. This approach, however, may take years to advance understanding. We are certain today that formaldehyde at high exposure levels increases nasal cancer in rats and mice. We are still debating whether or not humans exposed to far lower levels of formaldehyde are at any increased risk of cancer of the upper respiratory tract. As for the new leukaemia hypothesis, I suspect we are many years from resolution, but we do not have the "freedom to ignore the knowledge we already have, or to 
postpone the action that it appears to demand".

Occup Environ Med 2004;61:875-876. doi: 10.1136/oem.2004.014324

Correspondence to: Dr J J Collins, Dow Chemical Co. 1803 Building, Midland, Michigan 48674, USA; iicollins@dow.com

Do not cite or quote this publication without permission of first author.

\section{REFERENCES}

1 Hill AB. The environment and disease: association or causation? Proc $R$ Soc Med 1965;58:295-300.

2 IARC. IARC monographs on the evaluation of carcinogenic risks to humans. Vol. 62: Wood dust and formaldehyde. Lyon, France: IARC, 1995.

3 Blair A, Saracci R, Stewart PA, et al. Epidemiologic evidence on the relationship between formaldehyde exposure and cancer Scand J Work Environ Health

1990;16:381-93.
4 Hauptmann M, Lubin JH, Stewart PA, et al. Mortality from lymphohematopoietic malignancies among workers in formaldehyde industries. J Natl Cancer Inst 2003;95:1615-23.

5 Pinkerton LE, Hein MJ, Stayner LT. Mortality among a cohort of garment workers exposed to formaldehyde: an update. Occup Environ Med 2004:61:193-200

6 Coggon D, Harris EC, Poole J, et al. Extended follow-up of a cohort of British chemical workers exposed to formaldehyde. J Natl Cancer Inst 2003;95:1608-15.

\section{Clinical Evidence-Call for contributors}

Clinical Evidence is a regularly updated evidence based journal available worldwide both as a paper version and on the internet. Clinical Evidence needs to recruit a number of new contributors. Contributors are health care professionals or epidemiologists with experience in evidence based medicine and the ability to write in a concise and structured way.

\section{Currently, we are interested in finding contributors with an interest in} the following clinical areas:

Altitude sickness; Autism; Basal cell carcinoma; Breast feeding; Carbon monoxide poisoning; Cervical cancer; Cystic fibrosis; Ectopic pregnancy; Grief/bereavement; Halitosis; Hodgkins disease; Infectious mononucleosis (glandular fever); Kidney stones; Malignant melanoma (metastatic); Mesothelioma; Myeloma; Ovarian cyst; Pancreatitis (acute); Pancreatitis (chronic); Polymyalgia rheumatica; Post-partum haemorrhage; Pulmonary embolism; Recurrent miscarriage; Repetitive strain injury; Scoliosis; Seasonal affective disorder; Squint; Systemic lupus erythematosus; Testicular cancer; Varicocele; Viral meningitis; Vitiligo However, we are always looking for others, so do not let this list discourage you.

\section{Being a contributor involves:}

- Appraising the results of literature searches (performed by our Information Specialists) to identify high quality evidence for inclusion in the journal.

- Writing to a highly structured template (about 2000-3000 words), using evidence from selected studies, within 6-8 weeks of receiving the literature search results.

- Working with Clinical Evidence Editors to ensure that the text meets rigorous epidemiological and style standards.

- Updating the text every eight months to incorporate new evidence.

- Expanding the topic to include new questions once every 12-18 months.

If you would like to become a contributor for Clinical Evidence or require more information about what this involves please send your contact details and a copy of your CV, clearly stating the clinical area you are interested in, to Claire Folkes (cfolkes@bmigroup.com).

\section{Call for peer reviewers}

Clinical Evidence also needs to recruit a number of new peer reviewers specifically with an interest in the clinical areas stated above, and also others related to general practice. Peer reviewers are health care professionals or epidemiologists with experience in evidence based medicine. As a peer reviewer you would be asked for your views on the clinical relevance, validity, and accessibility of specific topics within the journal, and their usefulness to the intended audience (international generalists and health care professionals, possibly with limited statistical knowledge). Topics are usually 2000-3000 words in length and we would ask you to review between 2-5 topics per year. The peer review process takes place throughout the year, and our turnaround time for each review is ideally 10-14 days.

If you are interested in becoming a peer reviewer for Clinical Evidence, please complete the peer review questionnaire at www.clinicalevidence.com or contact Claire Folkes(cfolkes@bmigroup.com). 